\title{
LIBERTAD CONDICIONAL: \\ SUBJETIVIDAD POLÍTICA E HISTÓRICA EN HEREJES
}

\author{
POR \\ JonATHAN DETTMAN \\ University of Nebraska at Kearney
}

Herejes (2013) es una obra extensa. Entre las novelas de Padura, sólo El hombre que amaba a los perros (2009) tiene una extensión comparable. En términos de su ambición historiográfica, ninguna la iguala, pues Herejes abarca no sólo dos hemisferios sino cinco siglos. En realidad, la obra es triple, encerrando tres "libros" (Daniel/Elías/Judith) que podrían ser novelas independientes a pesar de que conforman las etapas de una saga familiar.

En el plano temático de la novela, el concepto de libertad individual se enfrenta constantemente a su contrario, la heteronomía o voluntad ajena. La recurrencia de este tema es de esperar en una obra que celebra y conmisera con los herejes, esos seres inconformes que responden primero a sus exigencias internas que a cualquier dogma político o social.

En el plano formal, lo que une los tres libros son ciertos objetos emblemáticos. El uso de objetos para encerrar una historia o para unificar hilos narrativos es frecuente en la novelística de Padura. Podemos destacar el disco de boleros en La neblina del ayer (2005) y el manuscrito de Heredia en La novela de mi vida (2002) como elementos físicos que encierran un misterio al mismo tiempo que revelan el pasado. En Herejes, dos de estos elementos, el retrato pintado por Rembrandt van Rijn y la película Blade Runner (1982), son notables por lo que contribuyen a la unificación de la obra. Hay un tercer elemento, menos importante para la cohesión de la novela que para lo que ilumina del subtexto político-económico, que es la figura de Kurt Cobain, representada por un afiche y una cita asociados con Judith, la joven desaparecida del tercer libro.

EL RETRATO - LIBERTAD BAJO CUSTODIA

El enigma que domina dos tercios de Herejes (los libros de Elías y de Daniel) es el origen y paradero de un pequeño lienzo con el retrato de un judío que se parece 
a Cristo. El judío resulta ser Elías Montalbo de Ávila, vástago de judíos sefardíes emigrados desde Portugal hasta una Holanda en vías de convertirse en el centro financiero más poderoso del mundo. Elías fue retratado por el mismísimo Rembrandt, con quien sostuvo una relación de aprendizaje a pesar de las prohibiciones judías contra la pintura, considerada una forma de idolatría.

$\mathrm{Al}$ cabo de una serie de eventos que se dilata a través de varios siglos -desde el Levantamiento de Jmelnytsky (1648-1654) hasta el nefasto episodio del MS St. Louis (1939) en el que más de novecientos judíos refugiados fueron devueltos a Europa (Amberes) tras haber sido rechazados en Cuba, Estados Unidos y Canadá- el retrato queda en manos de un funcionario cubano cuando sus dueños trataron de comprarse el desembarco en La Habana. Los Kaminsky, el clan disperso que protagoniza toda la novela, fueron despojados por aquel oficial mezquino y terminaron sus días en un campo de concentración cerca de Varsovia, de donde se habían querido escapar. Sólo sobrevivieron el hijo, Daniel, y el tío Joseph, quienes se habían instalado en Cuba un tiempo antes.

En el cuadro robado se plasma el principal mensaje ideológico de Herejes, que es toda una polémica sobre la libertad. Por medio de reiterados contrastes entre heterodoxos y ortodoxos, libertarios y dogmáticos, la libertad queda expuesta como el valor supremo. Iberia es recordada por los sefardíes como la tierra de idolatría, donde la fe católica fue impuesta a la fuerza. Holanda, con su liberalismo político y económico, es vista como la tierra de libertad (205). Sin embargo, hay dejos de una realidad socioeconómica holandesa que limita algunas libertades -Elías es consciente de divisiones de clase y discriminación contra los judíos- pero éstos no alteran el cuadro general de Amsterdam, en el que, respecto al joven pintor, son elementos foráneos, mayormente askenazíes de Polonia, quienes son responsables por las represalias contra herejes. Al contrario, la libertad es asociada con el sabio y liberal Ben Israel y, sobre todo, con el maestro Rembrandt, autor de varias declaraciones al respecto. En boca de estos librepensadores se colocan enunciados como los siguientes: "Para un artista todos los compromisos son un lastre: con su Iglesia, con un grupo político, hasta con su país" (235); "la libertad es el mayor bien del hombre" (235).

A primera vista, la visión artística de Rembrandt no admite compromisos de ninguna índole. Expresa un concepto del artista que lo es por un llamado impostergable de su propia naturaleza, una figura fáustica que sólo obedece el impulso creativo de su fuero interno. La repetición incesante del tema de la libertad, junto con la ambición histórica de la novela, que intenta hilvanar una ciudad y una época remotas con el presente cubano, revela una intención universalizadora. Se pretende establecer correspondencias entre "herejes" en ambos contextos para que el lector lea en términos contemporáneos las críticas adelantadas hacia "pastores de destinos colectivos" (238) u "hombres capaces de condenar con una nidoy a un hijo porque mantenía relaciones con un padre que vivía en Portugal o en España" (239). 
Los paralelos con la Cuba actual pueden parecer forzados porque no hay nada fuera de esta insistencia en herejes vs. ortodoxos que nos obligue a considerar que las dificultades de un judío en Amsterdam tengan algo que ver con el presente cubano, no obstante el recurso del cuadro heredado y venido a parar en La Habana.

Afortunadamente, el asunto se complica, pues resulta que Rembrandt, la encarnación de la libertad artística, tiene menos libertad que sus declaraciones harían suponer. El maestro no es exento de un pragmatismo necesitado por su condición económica, siempre marginal y precaria, debido a sus deudas y el costo de mantener su vida pequeñoburguesa. Tampoco puede ejercer plenamente su albedrío artístico. Está sujeto a normas impuestas por el gusto reinante por una belleza sencilla, que no molesta. En la narración aparece varias veces el cuadro La ronda de noche, que supuestamente generó una controversia por no elogiar a los notables holandeses ni reforzar los mitos fundacionales de la nueva potencia económica. Este cuadro y otros que no complacían los gustos de los compatriotas de Rembrandt hicieron que él sintiera el impacto económico de una falta de encargos. La solución encontrada fue dedicar una parte de su labor a la exigencias del mercado y otra parte a sus propios criterios (Herejes 268).

La teoría del arte esbozada por la novela se examinará con más atención en la próxima sección, pero desde ahora resulta oportuno señalar que esta teoría, a pesar de basarse en el artista autónomo, está llena de contradicciones que limitan esa autonomía. Pintar puede corresponder a un motivo interno, pero en una escena que describe a Elías en el acto de realizar un retrato de su novia, se hace evidente que alcanzar "lo sagrado" (290) en el arte depende de la verosimilitud, de "haber reflejado la mirada" (290), del "díalogo [del pincel] con el resto de los detalles del rostro" (290) y, en fin, de la relación entre el sujeto y el objeto. Tal relación es diálectica e impone estrictos límites en la libertad del artista, ya que su arte no surge solamente de su propia alma, sino de su aprehensión de algo exterior. Asimismo, tal tensión productiva entre sujeto y objeto está implícita en la relación entre el individuo y la sociedad, pues la libertad del sujeto se expresa siempre dentro de un marco social.

\section{BLADE RUNNER - SUBJETIVIDAD NARRATIVA Y POLÍTICA}

La película Blade Runner ejerce una extraña fascinación sobre Mario Conde. En Herejes hay un episodio en el que el detective, borracho y perdido en sus reminiscencias, se lanza desnudo al mar, tratando de detener la puesta del sol. En medio de su confusión y atolondramiento recuerda el monólogo conocido como "Lágrimas en la lluvia", que en la mente de Conde se asocia, de alguna forma, con su incapacidad de detener el tiempo y recuperar lo perdido. El motivo de la película recurre una y otra vez en el curso de la investigación sobre la muerte de Judith (Judy) Torres, una joven conectada de forma tangente con el retrato de Elías.

$111 \frac{\text { Revista Iberoamericana, Vol. LXXXV, Núm. 269, Octubre-Diciembre 2019, }}{1243-1255}$ 
En su conversación con la socióloga Eugenia Cañizares, a la que Mario Conde acude en busca de respuestas sobre la ideología de la joven víctima, el detective se da cuenta de la calle sin salida en la que Judy y su generación se encuentran: "-Chico, la cosa es que esos muchachos no creen en nada porque no encuentran nada en que creer" (432). Explica la doctora que "esos jóvenes están expresando un sentimiento generacional bastante extendido. Son el resultado de una pérdida de valores y categorías, del agotamiento de paradigmas creíbles y de expectativas de futuro que recorre a toda la sociedad [...]" (431).

Uno de los rompecabezas implicados en el tema del libre albedrío (esbozado en la sección anterior) es el dilema del individuo frente a la sociedad. Una versión cubana de este dilema es el derecho individual dentro de un proceso popular como lo fue la Revolución. ¿Puede alguien exigir derechos - de propiedad, de expresióny avanzarlos contra los intereses de todo un pueblo? La respuesta oficial ha sido negativa - todo dentro de la Revolución- pero la réplica popular ha sido más variada. Algunos se han mantenido firmes en sus convicciones revolucionarias, confiados en la capacidad del alto mando para navegar la crisis del socialismo. Otros se han ido. La mayoría se ha adaptado a las nuevas circunstancias, luchando y resistiendo y acercándose cada vez más a una ética empresarial (cuentapropista). Como Mario Conde, quien ha "perdido casi todas las expectativas que no est[án] relacionadas con la más vulgar supervivencia” (27), hacen de la necesidad virtud, sin preocuparse demasiado por cuestiones ideológicas. El materialismo dialéctico ni se come ni se vende.

Dado este panorama general, en el que las convicciones políticas han cedido terreno al nuevo espíritu empresarial, cabe preguntar hasta qué punto Herejes refleja las nuevas circunstancias del país. Efectivamente, Stephen Wilkinson ha criticado la novela por haber perdido de vista los cambios más recientes. ¿Por qué insiste la novela en la circunstancia de estar atrapado si los cubanos pueden viajar libremente ahora? ¿Por qué insiste Padura en ofrecer un panorama tan sombrío cuando todo se mejora en éste, el mejor de los mundos posibles? Si bien los cubanos pueden viajar (siempre y cuando tengan los recursos necesarios), la sensación de estar atrapado no es limitado al sentido literal de no poder salir de la isla. Si se atiende al texto, todo indica que Judy no quiso irse. Todos sus amigos, amantes y parientes confirman que su intención no fue salir, lo cual queda comprobado por el desenlace.

Importa señalar que Mario Conde es más que un protagonista -también focaliza una conciencia histórica que, por un lado, pretende representar a una generación de cubanos y, por otro, intenta universalizar aspectos de su experiencia-. El carácter universalizador de la obra es fundamental, ya que representa a un tiempo su punto más débil (la torpe insistencia en dibujar paralelos más o menos explícitos entre épocas) y su aspecto más fuerte, que consiste en el mismo Mario Conde como recurso

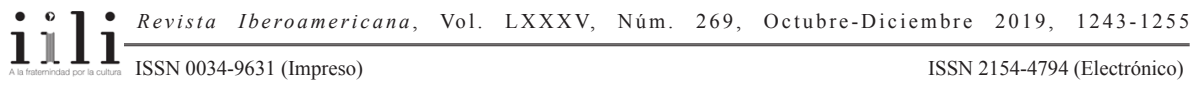


de formalización estética. El crítico brasileño Roberto Schwarz, en un ensayo en el que atribuye sus mejores ideas a Antonio Candido, define "formalización estética" como el proceso de transformar una forma o dinámica social en una estructura literaria (132). En este sentido, Mario Conde es el mayor hallazgo de Padura, pues no sólo es un "personaje" sino también una dimensión formal de su obra que permite la aprehensión de la realidad social cubana.

Conde, como representante de su generación, es desilusionado y "cada vez más jodido", como no cansa de recordarse. Al mismo tiempo, preserva el idealismo de los primeros años revolucionarios en que se formó. Es un tipo con una profunda empatía, capaz de asimilar experiencias y perspectivas ajenas y alterar sus propias actitudes cuando éstas le parecen anticuadas o imperfectas. Esta empatía hace que en el personaje Conde se acumulen muchas perspectivas, convirtiéndolo en un punto de encuentro para experiencias diversas que, a través de él, se vuelven mutuamente comprensibles. Ahora, en el octavo episodio de la serie "Mario Conde" (si se incluye La cola de la serpiente [2011]), el detective es autoconsciente de un modo casi exagerado, un "cabrón recordador" en el que el efecto cumulativo de dos décadas de investigación criminal y observación social produce divagaciones constantes y referencias a las novelas anteriores. Conde es capaz de comprender cabalmente su propia situación histórica y tender puentes entre la experiencia cubana y la de un judío muerto hace más de tres siglos, así universalizando su experiencia. Sin embargo, el detective es incapaz de alterar el curso de esa historia. No es uno de los "dueños de la Historia" capaces de manipular la autoimagen nacional (el ejemplo es de La novela de mi vida). $\mathrm{Al}$ contrario, fue un iluso que, como integrante de un proyecto revolucionario, sintió el motor de la historia bajo su pulso, sólo para quedar perplejo cuando ese motor se vio incapaz de mantenerse al ritmo de las corrientes en las que navegaba.

La tendencia hacia la universalización, arraigada en la profunda empatía del personaje, es posibilitada por la circunstancia de estar rodeada, no del agua por todas partes, sino de poderes impersonales que parecen manejar destinos y limitar el albedrío individual. Lejos de ser una manifestación de paranoia, la sensación de ser manipulado por fuerzas invisibles -frecuente en la literatura y el cine negrospuede atribuirse a un aspecto de la modernidad capitalista que el historiador Moishe Postone ha llamado dominación social, un conjunto de imperativos y restricciones impersonales que no puede entenderse en términos del dominio de personas o grupos particulares (4). Esta experiencia compartida permite la exploración literaria de paralelos entre épocas tan diversas como el Período Especial, la década de los 60 en Cuba, la Guerra Civil Española y la Ámsterdam del siglo XVII.

Un lector de Padura podría objetar, observando que en muchas ocasiones Conde culpa a los corruptos y amorales ladrones que se han aprovechado de la confianza del pueblo-Rafael Morín, Alcides Torres, etc.-. Es el caso, sin embargo, que cuando estos 
individuos son ajusticiados, legal o kármicamente, no se alteran las características de la sociedad. Todo sigue igual porque el mal es sistémico. De la misma forma, el cambio de orientación del gobierno y el hecho de que ya existan libertades formales como el derecho a viajar o a armar un negocio no quiere decir que muchos cubanos tengan esas libertades in re, y los ensalzados cambios significan poco para los que quedan "sin fuerzas ni edad para reciclarse como vendedores de arte o gerentes de corporaciones extranjeras" (Herejes 24).

Como se ha indicado anteriormente, la falta de libertad (o la presencia de una libertad solamente formal) es el eje temático de la novela. El hecho de que los cambios políticos y económicos en Cuba no hayan producido la auténtica autonomía del ciudadano hace que el sujeto que está experimentando esos cambios perciba la falta de autonomía (viz. heteronomía) como un atributo universal de la experiencia humana, con consecuencias para el desarrollo de una novela narrada desde esta subjetividad. Aunque parezca que "El libro de Elías" no tiene narrador identificable, la perspectiva de la novela entera no puede distinguirse de la de Mario Conde.

La selección de la Ámsterdam de Rembrandt y Spinoza como fondo histórico de "El libro de Elías" no es casual. La noción del libre albedrío no puede situarse antes de esta época, pues fue en la misma Holanda del siglo XVII donde Descartes escribió Discurso del método (1637), con su doctrina del cogito monadológico. No puede haber albedrío donde no hay subjetividad, y formulaciones anteriores de la libertad de elección (como la de Aquinas) se limitan a la posibilidad de seleccionar el modo de llegar a un fin predeterminado por la deidad. El arte barroco del periodo, dentro y fuera de Holanda, era campo de batalla entre visiones del arte y del artista y su relativa libertad frente a la tradición.

Si en el Barroco existía una tensión entre el respeto por autoridades y tradiciones y el concepto del individuo voluntarioso (Beverley 225) al lado de un debate sobre la primacía de la voluntad divina sobre la humana (Gray), esa tensión aún no se había resuelto a favor del individuo. El Barroco, con una de sus dos caras contemplando el mundo precapitalista y precartesiano (Beverley 216), no acababa de adoptar la idea del auteur que se vería más de un siglo después en el Romanticismo. Sin embargo, Eric Jan Sluijter indica que en Rembrandt y sus admiradores ya se notaba el principio individualista de "talento" (126), expresado en la capacidad de pintar "de la vida" (123). En la novela vemos la misma preocupación por el realismo, que es consistente con lo que se sabe del Rembrandt histórico. "Sé muy bien que el estatúder no quiere exhibir en su palacio pies sucios ni pastores andrajosos recién salidos del desierto, como debió haber sido en realidad. No quiere vida: solo una imitación de ella que resulte bella" (Herejes 269).

Elías Montalbo exhibe la misma preocupación por representar la esencia vital del modelo, pero su religión lo lleva más allá de su maestro. Como buen aprendiz, Elías trata de imitar al maestro. Trabaja en su casa, observa su técnicas de producción, etc.

$111 \frac{\text { Revista Iberoamericana, Vol. LXXXV, Núm. 269, Octubre-Diciembre 2019, } 1243-1255}{\text { ISSN 2154-4794 (Electrónico) }}$ 
Pero desde el principio de su aprendizaje, Elías trata de justificar su predilección por la pintura en términos religiosos, llegando a convencerse de la trascendencia de su actividad artística, que en realidad era una expresión de la voluntad de Dios, quien obra a través de manos humanas. "[N]ada puede el Creador, en cuestiones terrenas, sin la voluntad y el raciocinio de su engendro más indómito" (202). Aquí Elías hace eco de su contemporáneo histórico Baruch Spinoza, autor de un tratado titulado "Crítica a la religión tradicional", donde afirma que los seres humanos son agentes de Dios (Spinoza 25).

Elías entiende su oficio como "el poder de la Creación, el impulso de la trascendencia" (241) y, bajo la presión de la ortodoxia judía, llega a una visión de sí mismo muy alejada del imitador de la natura o incluso de ser conducto para una voluntad superior: "Y si sus pinceles o carbones lograban captar la vida palpitante en aquella mirada, entonces habría sido capaz de ejercer el poder de atrapar un atisbo tangible de lo sagrado. Como un dios" (276). En esta formulación, el artista se parece más al demiurgo romántico que al ingenioso barroco que, si bien mostraba un espíritu independiente e incluso creía en la inspiración celestial, no se atribuía poderes divinos.

El joven artista acaba convirtiendo la compulsión exterior en una especie de libertad interior que no puede ser expresada en público. La comunidad le niega la pintura, pero Dios se la obliga. En todo caso sigue siendo una compulsión. El último paso, la verdadera herejía (tanto en términos del dogma como respecto a la verosimilitud histórica del personaje), es imaginarse un dios en su fantasía de poder creativo (241) y procreativo (284). La tragedia de Elías (que recurre en "El libro de Judith") es que su fantasía de libertad de creación sui generis o subjetiva no alteró la realidad objetiva de una comunidad que lo expulsaría.

El leve anacronismo del artista-demiurgo deja asomar una perspectiva posterior al siglo XVII, lo cual es lógico si se presta atención a la factura (estructura) de la novela, que se abre y se cierra con una focalización en Mario Conde. Las páginas finales de la novela incluso presentan a Elías Montalbo como una construcción mental del detective, quien ha tenido que reconstruir la vida del judío a través de la historia del cuadro y la carta descubierta por Elías Kaminsky. "Detrás de los ojos de Mario Conde, en su mente, estaban abiertos los ojos del joven judío E.A., aprendiz de pintor" (513). A través de detalles como éstos, se puede notar cómo Padura, por medio de Conde (su instrumento de formalización estética), recrea el pasado desde la perspectiva actual y cómo trata de reconciliar (universalizar) la experiencia de "herejes" de varias épocas. Padura mismo parece favorecer una noción de autoría cercana a la de Elías, pues un ensayo sobre la génesis y evolución del personajenarrador Mario Conde lo tituló "El soplo divino: crear un personaje".

Volviendo ahora a la cuestión del albedrío en el contexto cubano, la incapacidad del sujeto para intervenir en el terreno político produce una especie de estancamiento. En el caso de Conde, la falta de horizonte ideológico desemboca en una nostalgia

$111 \frac{\text { Revista Iberoamericana, Vol. LXXXV, Núm. 269, Octubre-Diciembre 2019, }}{1243-1255}$ 
por los años idealizados de su juventud y de la Revolución. En Judy, la ausencia de una política grupal produce un tribalismo (la fractura de los jóvenes en sectas identificables, no por sus creencias, sino por la moda) y una interiorización del impulso político como el problema del cuerpo/espíritu.

Judy y sus amigos resultaban la punta visible y más llamativa del iceberg de una generación de herejes con causa [... L]a falta de fe y de confianza en los proyectos colectivos había generado la necesidad de crearse intenciones propias y el único camino entrevisto por aquellos jóvenes para llegar a esas intenciones había sido la liberación de todos los lastres. No creer en nada sino en sí mismos y en los reclamos de la propia vida, personal, única y volátil. (442)

El dilema del individuo frente a la sociedad y el problema político del derecho del individuo frente al derecho de las masas se convierten en una lucha interior en la que el espíritu (principio de voluntad o libertad) se enfrenta al cuerpo (prisión del espíritu).

De ahí la importancia de Blade Runner (Herejes 197, 375, 431, 434, 437, 449, 488) como motivo recurrente en la novela. La tragedia de los replicantes -unos robots idénticos a los seres humanos, destinados a ser esclavos y no pisar la Tierra (so pena de muerte si son descubiertos)- es que tienen voluntad de ser libres aun cuando su cuerpo es prisionero o está condenado a morir. Los replicantes son utilizados por Padura como un símbolo del yo pensante (o sujeto) que alcanza su límite al enfrentarse con las fronteras sociales y/o biológicas. El cuerpo es un límite análogo a la sociedad en términos de las restricciones que impone a la libertad individual; la reducción al cuerpo del ámbito de esta libertad representa la interiorización del impulso político.

\section{KuRT CoBAIN - LA MIGRACIÓN DE LA REBELDÍA}

En "El libro de Judith", la tercera novela incrustada en Herejes, una joven emo cita, como consigna de identidad grupal, un verso que ella atribuye a Kurt Cobain: "It's better to burn out than to fade away." La cita, en realidad, corresponde a la canción "Hey Hey, My My (Into the Black)", grabada por Neil Young en 1978 y citada por Cobain en su nota suicida.

Cobain fue el torturado frontman de Nirvana, el trío grunge que encabezó el último gran éxito del rock en el mercado norteamericano (Cobain se suicidó en 1994). Nirvana y otras bandas afines del Seattle Scene fueron el último grito de rebeldía rockera antes de que ese capítulo de la historia musical fuera cerrado. Según Joshua Clover, el grunge, etapa final del ciclo rock, fue una inversión psicologista del impulso explícitamente político visto en etapas anteriores (73-89) -en el optimismo de los 60 tan añorados por Conde, o en la rabia y militancia del punk-. El hecho de

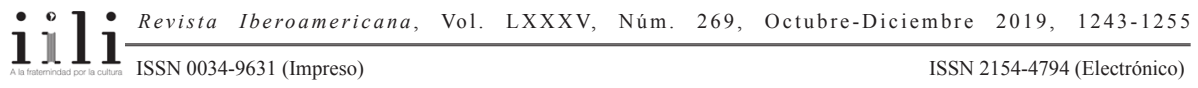


que Cobain aparezca aquí como emblema de unos jóvenes de la generación possoviética no puede ser casual.

Tampoco es casual la aparición de la cofradía emo para representar un sector juvenil caracterizado por su rechazo del modelo político cubano. Los sociólogos han identificado una marcada tendencia generacional hacia un alejamiento de la política revolucionaria y hasta de la generación anterior (Krull y Kobayashi). Esta realidad social encuentra su eco en el susodicho diagnóstico de la doctora Cañizares.

Los emos de la novela, según ellos mismos, se niegan a identificar con el poder institucional o los dogmas oficiales. "No nos dejamos tratar como corderos, vamos a vivir la vida que nos da la gana y no le vamos a rendir pleitesía a nadie, ni hombre ni dios" (360). Esta actitud rebelde caracteriza a casi todas las corrientes contraculturales, aun los que no profesan de forma explícita el "ni dios, ni amos" anarquista. Lo que distingue a los emos es su ensimismamiento emocional, el placer morboso derivado de dejarse deprimir e incluso de hacerse daño. El emo, tanto como género musical como modo de vivir, consiste precisamente en desentenderse del mundo político y en sumergirse en las profundidades afectivas del yo cartesiano. "Una es emo porque es emo. Porque nos duele vivir en un mundo podrido y no queremos saber nada de él" (341).

Al despedirse del grupo de emos tras un encuentro que desató un conflicto generacional y ético entre Yoyi (el socio de Conde) y Yovani (el joven que será implicado en la muerte de Judy), el detective Mario Conde se disculpa: "Perdonen a mi amigo... Él es así, impulsado. Es que fue rockero" (361). En este encuentro se esboza una diferencia fundamental. Al contrario de Conde y Yoyi, formados antes de la crisis de los 90, los jóvenes emos pertenecen a un momento pos político caracterizado por la inversión o interiorización del impulso herético y antisistema. La novelística de Padura encuentra sus coordenadas precisamente en este período pos revolucionario, inaugurado por la crisis soviética y dilatado a través de dos décadas de pasos lentos hacia algo que ya no se reconoce como socialismo. "Ésta, entonces, es la situación. El antagonismo que había sido la historia del siglo y que le había proporcionado su estructura y, por lo tanto, su navegación, ha desaparecido" (Clover 127; mi traducción). En esta coyuntura, no hay rutas claras por donde canalizar impulsos políticos, y la rebeldía se interna en la mónada psicológica del individuo.

Si el grunge fue parte de la lógica cultural de ese giro reflexivo, el emo fue un eco en el que no quedaron vestigios de rebelión. El rock ha dejado de ser vehículo masivo de pasiones revolucionarias, que ahora encuentran su expresión en otros fenómenos culturales. La tragedia de Judy (y de los otros "herejes") es la del sujeto revolucionario en un ambiente reaccionario.

La joven, propensa a tomar a pecho las ideas de los emos e ir más allá de un grupo a la que la mayoría se había integrado "por moda o imitación” (399), es un

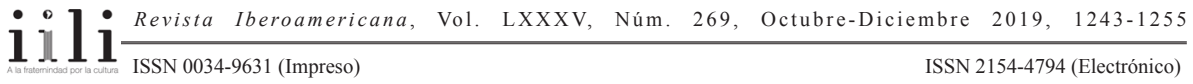


auténtico rebelde. Sus lecturas (de Nietzsche, de Cioran) indican que ha intentado profundizarse en temas como la corporeidad y la libertad del espíritu.

Por lo tanto, el acto de suicidarse, según ella misma, hubiera sido un acto de liberación y de rebeldía, una escapatoria del "mundo de mierda" (358) que la rodeaba. El suicidio intenta reclamar la agencia individual frente a una sociedad caracterizada por la heteronomía. Como en la historia de Elías Montalbo, su rebelión se orienta hacia dentro, en torno a su identidad como emo. Donde Elías se otorga poderes divinos y creativos sobre la vida, Judith quiere gobernar la muerte. Ella no puede dañar el sistema, pero puede dañarse a sí misma. Que Yovany (el presunto culpable) le haya quitado esa opción es importante porque indica que la libertad puramente interior o personal no es más que una ilusión. La compulsión llega hasta el fuero interno.

\section{CONCLUSión}

Aunque Herejes es una obra que se esfuerza por universalizar la experiencia de los inconformes, es posible identificar el origen de esa perspectiva. Atendiéndonos a la construcción de la novela y a la forma en que todas las historias están dentro del marco subjetivo de Mario Conde, se puede afirmar, a pesar del alcance histórico de la obra, que el sujeto narrativo sigue anclado en la Cuba pos soviética, como es el caso de todas las novelas de Padura escritas desde los 90.

Por ello se percibe en Herejes una suerte de nivelación histórica, en la que todos los casos de opresión se convierten en una cuestión de inconformidad social frente a fuerzas que hacen conformar. De ese modo, la historia de Elías Montalbo a veces parece la extensión de una crítica de varios aspectos de la Cuba contemporánea: los Ortodoxos (fidelistas) se transforman en judíos ortodoxos y, sobre todo, la sensación de ser incapaz de alterar el curso de la Historia, experimentada como desencanto (Conde) o apatía (los emos), reaparece en un pintor abatido por fuerzas mayores (una comunidad conservadora, los cosacos, el fervor mesiánico).

Padura, desde la década de los 80 , ha estudiado la obra de Alejo Carpentier, sobre quien ha escrito numerosos ensayos. Sus análisis más recientes versan sobre el concepto de la libertad en El siglo de las luces (1962) y sobre la problemática de las revoluciones fracasadas o corrompidas en esa novela y en La consagración de la primavera (1978). La influencia de Carpentier se deja asomar en Herejes, donde los temas principales son precisamente la libertad y los falsos mesías.

Tal vez (como parece indicar Wilkinson) Herejes no esté a la altura de su modelo. ¿Quién puede alcanzar las cimas de un Carpentier, sobre todo bajo condiciones de producción muy alejadas de las del autor de El siglo de las luces? Algunos críticos se sienten obligados a pronunciar sobre la calidad artística de una obra (un criterio sujeto -siempre- a un "buen gusto" determinado, a su vez, por factores políticos y 
de clase), pero he preferido destacar los contextos que influyen en la forma y en la temática. Entre las condiciones de producción de El siglo de las luces y Herejes hay que contar la trayectoria de la Revolución. La primera de estas novelas fue terminada y publicada en el comienzo del proceso revolucionario; la segunda fue escrita durante su agotamiento.

No es siempre productivo hacer comparaciones entre autores cuyas perspectivas históricas varían tanto, pero el mismo Padura nos orienta respecto al asunto, señalando los retoques que Carpentier hizo (o podía haber hecho) a El siglo de las luces cuando la Revolución cubana desmintió (o pareció desmentir) el escepticismo y pesimismo expresado en cuanto a las posibilidades de los movimientos populares ("Revolución" 121-22). En la obra de Carpentier se buscó una solución estética (lo real maravilloso) que, según Neil Larsen, intentó trascender la dualidad del realismo y el modernismo (surrealismo) (118). Ello dio lugar a un concepto histórico que yuxtaponía o trasponía lo europeo y lo americano, "maravillando" al lector con algo parecido a "las ideas fuera de lugar" que, según Roberto Schwarz, también caracterizan la obra del gran realista brasileño, Machado de Assis (Larsen 121). Otra dimensión de lo real maravillosouna que es incluso su fuerza motriz - es la llamada "fe" sobre la que Carpentier erige su primera definición del concepto: "la sensación de lo real maravilloso presupone una fe" ("Prólogo" 8). Padura considera que esa fe es un legado antirracional, un vestigio de la primera formulación de lo real maravilloso a base del surrealismo, superado finalmente por la visión analítica de Carpentier (Un camino 385). Sin embargo, hay razones por dudar de esta opinión.

En una carta a José Antonio Fernández de Castro, fechada el 26 enero de 1933, Carpentier muestra su desdén por cuestiones puramente estéticas. "Arte aplicado hay muchas maneras de aplicarlo, insidiosamente, que resultan tan eficientes, a la larga, como los peores manifiestos. // ¿Belleza? Nuestras preocupaciones son DE OTRO ORDEN" (Chaple 20). El contexto de la cita hace evidente que el "otro orden" no es sino la Revolución comunista, que el novelista considera inminente en Europa. El arte, según Carpentier, debía comprometerse con la revolución. Esta convicción nunca fue abandonada por el escritor y, por lo tanto, es lógico que reapareciera dieciseis años después en el famoso prólogo a El reino de este mundo. En ese texto, Carpentier reprocha a los surrealistas y a otros artistas, no por razones estéticas, sino por su incapacidad de "jugarse el alma sobre el temible carta de una fe" (9). Inmediatamente después, invoca el ejemplo de los haitianos, cuya "fe colectiva", basada en el deseo de liberación, produjo un ser tan fantástico como Mackandal, quien "alentó una de las sublevaciones más dramáticas y extrañas de la historia" (10). La "fe" carpentieriana, lejos de ser un idealismo espiritual, no es sino una apuesta por la capacidad del pueblo para liberarse.

Independientemente de los retoques que Carpentier hizo (según Padura) a su novela, existe en su obra un optimismo acerca de las posibilidades revolucionarias. Al

$111 \frac{\text { Revista Iberoamericana, Vol. LXXXV, Núm. 269, Octubre-Diciembre 2019, }}{1243-1255}$ 
contrario, la obra de Padura, situada en el colapso definitivo de la Revolución, expresa un pesimismo profundo y exhibe un panorama político tétrico, tal vez exageradamente abismal, según el mentado Wilkinson. Y, más allá de su representación del entorno sociopolítico, Herejes, a diferencia de la novelística carpentieriana, no busca transponer épocas y cronologías, sino nivelarlas, pues todas parecen dar al mismo callejón sin salida.

No todo es pesimismo, sin embargo. A fin de cuentas, Padura no está muy lejos de expresar una fe similar a la confianza carpentieriana en la capacidad del pueblo para resistir y elevarse. Al afirmar la libertad como el mayor bien, se deja vislumbrar una chispa de optimismo irreductible surgida de la ética invencible de Conde: la idea de que, a pesar de todos los fracasos posibles, los seres humanos levantarán la cabeza y ejercerán su libertad. Tampoco queda descartada una política colectiva, ya que "solo vale la pena militar en la tribu que tú mismo has elegido libremente" (Herejes 513). Las tragedias de Elías y Judith (por no mencionar al no menos trágico Daniel) son una muestra contundente de lo ilusorio de la libertad individual en una sociedad que no es libre.

\section{BibLIOGRAFÍA}

Beverley, John. "On the Concept of the Spanish Literary Baroque." Culture and Control in Counter-Reformation Spain. Anne J. Cruz, ed. Minneapolis: U of Minnesota P, 1991. 216-30.

Blade Runner. Ridley Scott, dir. Con Harrison Ford, Rutger Hauer, Sean Young y Edward James Olmos. Warner Brothers, 1982.

Carpentier, Alejo. La consagración de la primavera. México: Siglo XXI, 1981.

Prólogo. El reino de este mundo. Barcelona: Seix Barral, 2000. 5-12.

El siglo de las luces. México: Compañía General de Ediciones, 1965.

Chaple, Sergio. "Carpentier en su epistolario con José Fernández de Castro". Alejo Carpentier: acá y allá. Luisa Campuzano, ed. Pittsburgh: Intituto Internacional de Literatura Iberoamericana, 2007. 15-22.

Clover, Joshua. 1989: Bob Dylan Didn't Have This to Sing About. Berkeley: U of California P, 2009.

Gray, Andrew Franklin. Makers and Creators: Human and Divine Artistry in Calderón. Diss. Harvard University, 2013.

Krull, Catherine y Audrey Kobayashi. "Shared Memories, Common Vision: Generations, Sociopolitical Consciousness and Resistance among Cuban Women." Sociological Inquiry 79/2 (2009): 163-89.

Larsen, Neil. Determinations: Essays on Theory, Narrative and Nation in the Americas. Londres: Verso, 2001. 
Neil Young \& Crazy Horse. "Hey Hey, My My (Into the Black)." Rust Never Sleeps. Reprise, 1979.

Padura, Leonardo. Un camino de medio siglo: Alejo Carpentier y la narrativa de lo real maravilloso. México: Siglo XXI, 2002.

Herejes. México: Tusquets Editores México, 2013.

El hombre que amaba a los perros. Barcelona: Tusquets, 2009.

La neblina del ayer. Barcelona: Tusquets, 2005.

La novela de mi vida. Barcelona: Tusquets, 2002.

"Revolución, utopía y libertad en El siglo de las luces". Yo quisiera ser Paul Auster. Madrid: Verbum, 2015.

"El soplo divino: crear un personaje". Yo quisiera ser Paul Auster. Madrid: Verbum, 2015.

Postone, Moishe. Time, Labor, and Social Domination. Cambridge: Cambridge UP, 2003.

Schwarz, Roberto. "Pressupostos, salvo engano, de 'dialética da malandragem'." Que horas são?: ensaios. São Paulo: Companhia das Letras, 2006. 129-55.

Sluijter, Eric Jan. "Rembrandt and the Rules of Art Revisited." Jahrbuch der Berliner Museen 51 (2009): 121-29.

Spinoza, Benedict y Edwin Curley. A Spinoza Reader. Princeton: Princeton UP, 1994.

Wilkinson, Stephen. "Mario Conde: el viaje más largo a ninguna parte". 19 feb. 2015. Catalejo: el blog de Temas. <www.temas.cult.cu/content/mario-conde-el-viajem-s-largo-ninguna-parte>. 16 jun. 2018.

Palabras clave: $\quad$ subjetividad - arte - albedrío - liberación - individualismo

Recibido: $\quad$ agosto 2016

Aceptado: $\quad$ mayo 2017 
